\title{
DCU development of diesel engines under V-type procedure
}

\author{
Cao Lin $^{1, a}$, Fan Wei ${ }^{1, b}$, Yue Guangzhao ${ }^{2, c}$ and Lei Yan ${ }^{3, d}$ \\ ${ }^{1}$ Shipbuilding information center of China, Beijing 100012, China \\ ${ }^{2}$ College of Environmental and Energy Engineering, Beijing University of Technology, Beijing \\ 100124, China \\ ${ }^{3}$ Institute of Engineering (Baotao), College of Engineering Peking University, Baotou 014030, China \\ aemial: 18504725480@163.com, ${ }^{b}$ emial: 13811445560@139.com, ${ }^{\mathrm{C} e m i a l:}$ \\ leiyan@bjut.edu.cn, demial: leiyan@bjut.edu.cn
}

Keywords: Diesel engine, SCR, DCU, V-type procedure

\begin{abstract}
Aimed at the selective catalytic reduction (SCR) system, an electronic control unit (DCU) was developed under V-type procedure. Development of DCU software and hardware were carried out simultaneously, shortening largely the development cycle. The self-developed DCU, integrated with Bosch SCR system, has a high NOx conversion efficiency without ammonia leakage, reaching almost $90 \%$ at mid and high engine load.
\end{abstract}

\section{Introduction}

The air pollution produced by nitrogen oxides, which comes from stationary and mobile combustion sources, has become a worldwide environmental problem [1][2][3][4]. For diesel engines, applying optimization technology in cylinders can not meet more stringent emission regulations any longer. After-treatment devices are equipped to largely reduce nitrogen oxides in exhaust gases. The application of SCR has been widely used in diesel engines [5]. The principle of SCR system is spraying aqueous urea solutions into the exhaust pipe of the diesel engine, reacting with nitrogen oxides and making it into harmless nitrogen and aqueous vapor [6][7]. The conversion efficiency of nitrogen oxides has its limit which is determined by the temperature of the catalyst and space speed. Therefore, the amount of aqueous urea should be enough to reduce nitrogen oxides, meeting harsh emission regulation limit. At the same time, usage dosage should not be excessive to cause ammonia leakage [8]. Therefore, the dosing strategy of aqueous urea solutions is an important part of DCU control algorithm.

DCU is a key component in the SCR system, especially its control algorithm. In this paper, a DCU was developed under V-type procedure. Comparing with the traditional development mode, V-type development is of more advantage. V-type development is model-based, which is able to verify control algorithm in the early development. Development of DCU software and hardware are synchronous, shortening the cycle of the whole DCU development.

\section{V-type procedure}

Fig. 1 shows the V-type development procedure of SCR in diesel engines. The first step is to define the functions of the SCR system, which is the control object. Secondly, development of DCU software and hardware are carried out simultaneously. The verification of DCU software algorithm is completed on rapid control prototype (RCP). The prototype PROtroniC is used in this paper, in which Matlab/Simulink 2012b is embedded. Thirdly, the code of DCU software algorithm is generated by using RTW tool in Matlab. With adding hardware drive code and manual amendment, the tool generated code can be download into DCU. Fourthly, DCU is tested in-the-loop on a testing platform. At last, experiments are conducted on the engine test bench. 


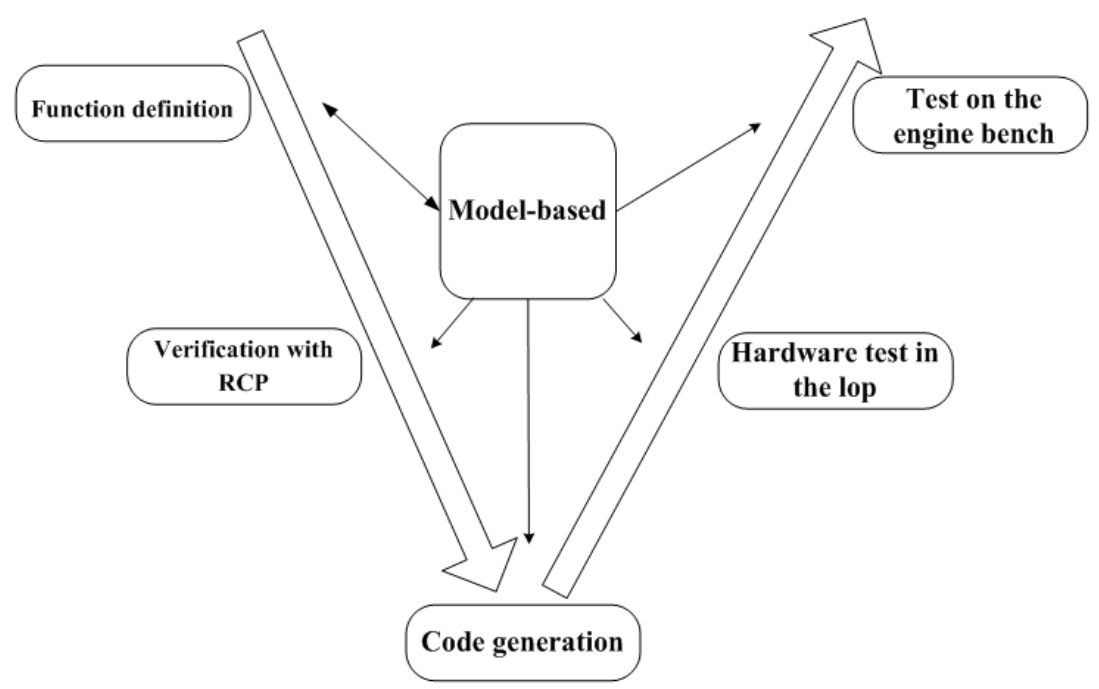

Fig. 1 block scheme of V-type procedure

\section{DCU function definition}

The function of DCU is shown in Fig. 2. The input of DCU are sensor signals in SCR system and signals acquired from ECU though CAN bus. Sensors are mainly includes urea pump pressure sensor, exhaust gas temperature sensors before and after SCR convertor, urea temperature sensor and urea liquid level sensor. Signals acquired from ECU are engine speed, torque, air intake temperature and pressure, exhaust gas mass flow, etc. The output of DCU is electric driving to several actuators, including the urea nozzle, the urea pump, return valve and heating relays of the urea tank, the urea pump, the urea nozzle and urea pipes. The main chip of DCU adopts Freescale microcontroller MC9S12XS256. The DCU circuit includes power drive circuit, input signal process, CAN communication and electric drive modules.

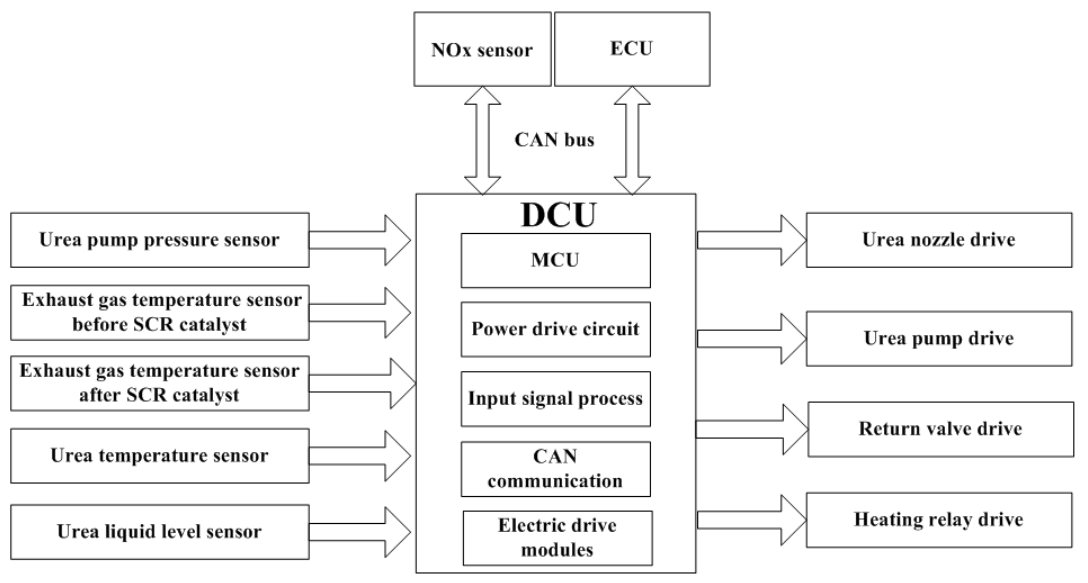

Fig. 2 block scheme of DCU functions

\section{Software development}

DCU software is developed based on Matlab/Simulink. The control strategy is completed in form of Simulink modules, concluding signal input process, signal output control, urea injection strategy and urea injection control. The function of injection strategy includes original NOx emission acquired though look-up table, required ammonia and urea mass flow calculation, the NOx conversion efficiency of the SCR catalyst estimation, etc. The function of urea injection control 
mainly includes dew point detection, operating state coordinate of SCR system, urea pressure control of the urea pump, control of the urea injection and the heating system, etc.

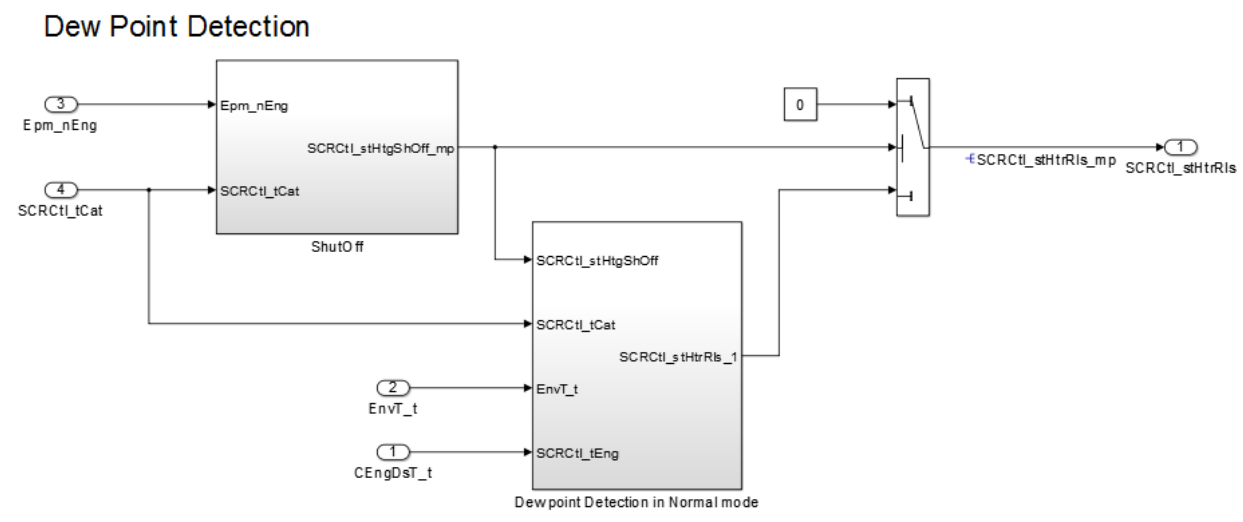

Fig. 3 Simulink module of dew point detection

Fig. 3 shows the simulink module of dew point detection. After engine cold starts, there is a risk that the NOx sensor ceramics, which is heated at $800^{\circ} \mathrm{C}$ is damaged or destroyed by condensing water droplets due to thermal shock. Depending on catalyst temperature and exhaust gas mass flow, the function of this module decides whether droplet formation in the exhaust gas system can be expected and supplies the release bit for NOx sensor heating which is the output block of this module 'SCRCtl_stHtrRls'.

\section{Hardware development}

DCU hardware is developed simultaneously as software development. In the following, urea nozzle drive is introduced, which is the most important drive module in the DCU circuit.

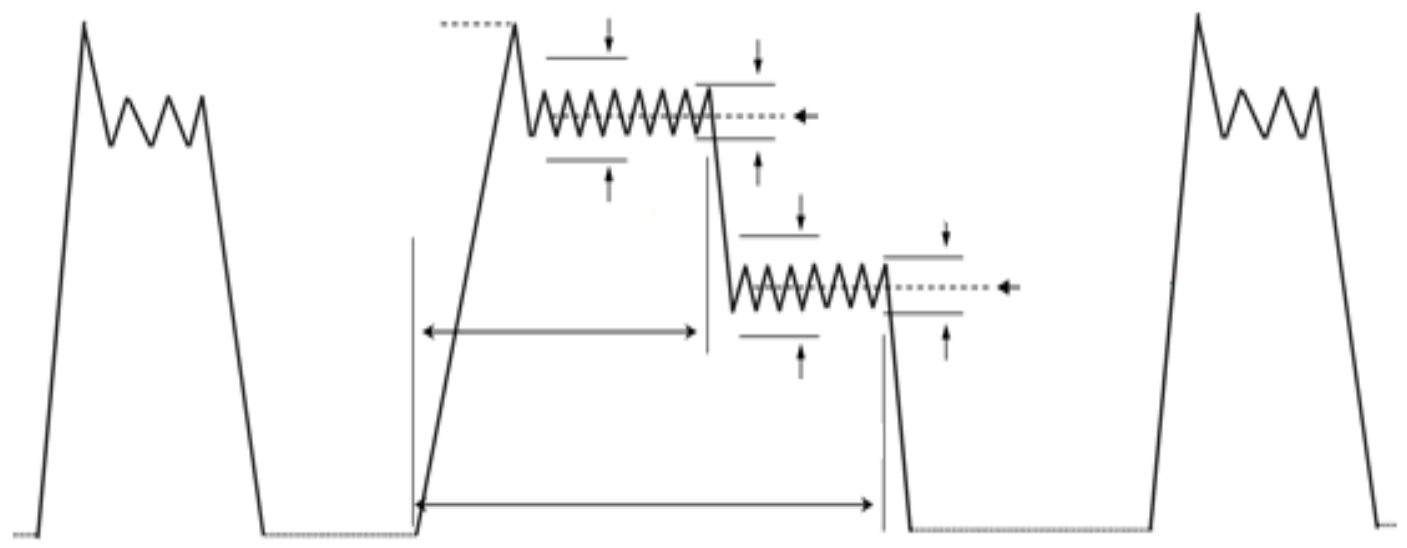

Fig. 4 Current flow of urea nozzle

The urea nozzle drive module is composed of high-end drive and low-end drive. The current flow of urea nozzle is shown in Fig. 4. In order to control accurately the peak current and the hold current, the urea nozzle drive adopts two periods of high-end drive. One is to make the current reaching the peak current in a short time, the urea nozzle opening quickly. The second is to achieve the hold current accurately, controlling the opening time of the urea nozzle.

In DCU circuit, UA9 chip is used to acquire such current to drive the urea nozzle. The peripheral circuit of the chip UA9 is shown in Fig. 5. Fig. 6 shows DCU physical picture. 


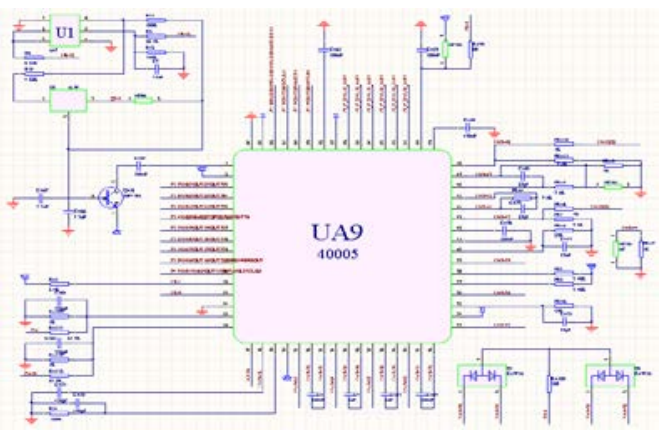

Fig. 5 the peripheral circuit of the chip UA9

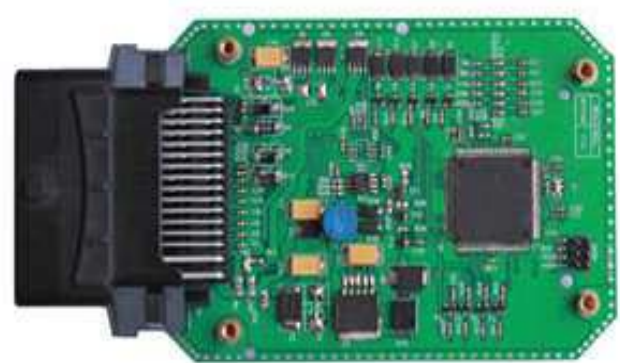

Fig. 6 DCU physical picture

In this paper, the prototype PROtroniC is used to verify the control strategy of DCU. The control strategy is embodied in the Simulink model, implementing the function of the SCR system. The model is divided into many sub-models for different functions. Upon completing one sub-model, verification of the sub-model with PROtroniC is conducted. If error existing, the model is modified promptly. Such developing mode removes error of DCU strategy quickly and shortens DCU development cycle. Using the RTW tools to generate code from the Simulink model, which can be downloaded to DCU hardware after manual amendment and adding hardware drive code.

\section{Experiments on the engine test bench}

To test the NOx treatment of the DCU developed in this paper, a test rig was constructed (see Fig. 7). Weichai WP 10 diesel engine was used. Table 1 shows the detailed engine specifications. The SCR system adopted Bosch product, only DCU was self-developed.

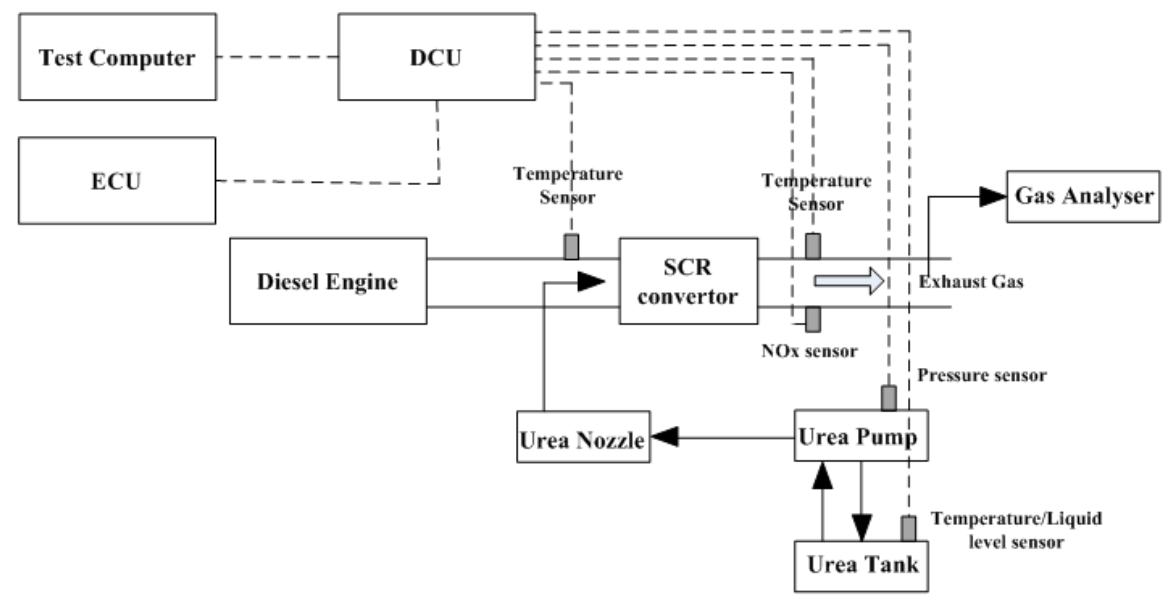

Fig. 7 Schematic of diesel engine test rig

Table 1 Engine specification

\begin{tabular}{ll}
\hline Property & Value \\
\hline Number of cylinder & 6 \\
displacement L & $9.726 \mathrm{~L}$ \\
Rated power $(\mathrm{kW} /(\mathrm{rpm}))$ & $247 / 2200$ \\
Maximum torque $((\mathrm{Nm}) /(\mathrm{rpm}))$ & $1250 / 1200-1600$ \\
Air intake & Turbocharged, intercooled
\end{tabular}

At the engine test bench, a series of tests under various operating conditions were conducted. A NOx sensor was seated on the exhaust gas pipe after the SCR convertor to measure NOx emission 
after treated by the SCR system. The NOx emission of the engine is acquired though a look-up MAP which is determined mainly by the engine speed and torque. In this paper, the NOx conversion efficiency is calculated based on the NOx emission of the engine and that after the SCR convertor. The gas analyser measured the NH3 emission, which is caused by excessive urea dosage.

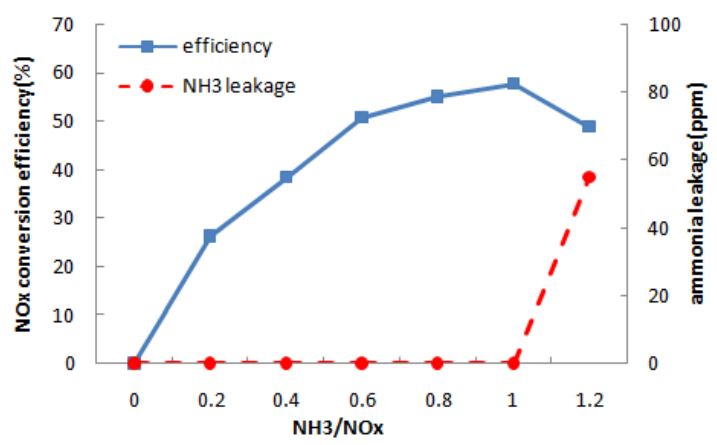

1) $1200 \mathrm{r} / \mathrm{min} 350 \mathrm{Nm}$

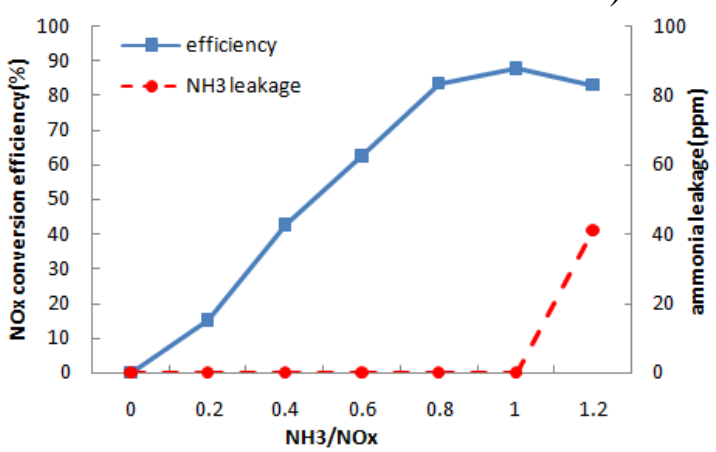

2) $1700 \mathrm{r} / \mathrm{min} 700 \mathrm{Nm}$

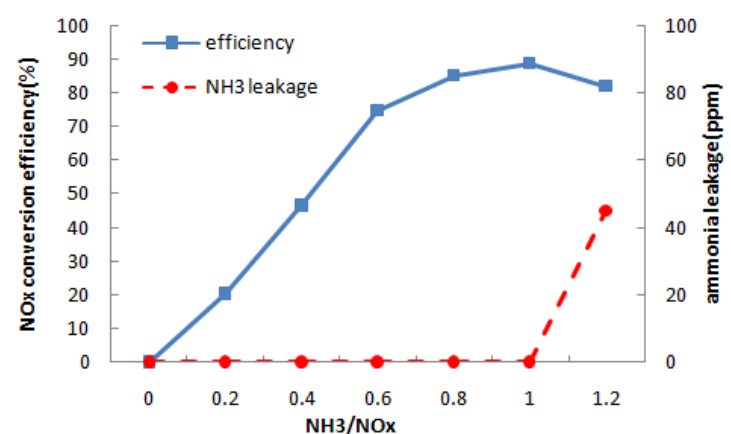

3) $1100 \mathrm{r} / \mathrm{min} 1100 \mathrm{Nm}$

Fig. 8 the NOx conversion efficiency under three different operating conditions

As shown in Fig. 8, experiments under three different operating conditions were conducted. As urea injection amount increasing, the ratio of $\mathrm{NH}_{3}$ hydrolyzed by urea to $\mathrm{NOx}$ emission of engine increases. The NOx conversion efficiency gets higher as the ratio of $\mathrm{NH}_{3}$ to $\mathrm{NOx}$ increases from 0 to 1. After the ratio of $\mathrm{NH}_{3}$ to $\mathrm{NOx}$ getting bigger than $1, \mathrm{NH}_{3}$ leakage occurs and the NOx conversion efficiency decreases. In fact, the $\mathrm{NH}_{3}$ dosage is excessive and the SCR convertor gets maximum capacity for reducing NOx emission. Because the NOx sensor is cross-sensitive for $\mathrm{NH}_{3}$, the $\mathrm{NOx}$ conversion efficiency decreases as $\mathrm{NH}_{3}$ leakage occurs. Therefore, the maximum of NOx conversion efficiency is obtained at the ratio of $\mathrm{NH}_{3}$ to NOx reaching to 1. From Fig. 8, it is found that the NOx conversion efficiency can reach $57 \%$ at $1200 \mathrm{r} / \mathrm{min}$, 350N.m and almost $90 \%$ at the other two operating condition. That is because the NOx conversion efficiency of the SCR convertor is mainly determined by the SCR temperature. At the operating condition of $1200 \mathrm{r} / \mathrm{min}$, 350N.m, the temperature of exhaust gases before the SCR convertor is 260C, which is measured by the temperature sensor before the SCR convertor. And at the operating condition 2 and 3, the temperature reaches to 400C and 490C, respectively. Therefore, the NOx conversion efficiency at middle and high engine load can gets a high level, approximately $90 \%$.

\section{Conclusions}

This paper developed a DCU under V-type procedure. The DCU developed in this paper, integrated with Bosch SCR system, has a high conversion efficiency in NOx treatment, reaching almost $90 \%$ at middle and high engine load. 


\section{Acknowledgement}

We gratefully acknowledge financial support for this work by National Key Technology Support Program (2013BAG25B01-04) and National Science Foundation of the inner Mongolia Autonomous Region (2014MS0501).

\section{References}

[1] Chiang C J, Kuo C L, Huang C C, et al. Model predictive control of SCR aftertreatment system, Industrial Electronics and Applications (ICIEA), 2010 the 5th IEEE Conference on. IEEE, 2010: 2058-2063.

[2] Qiu T, Li X, Lei Y, et al. The prediction of fuel injection quality using a NOx sensor for the on-board diagnosis of heavy-duty diesel engines with SCR systems[J]. Fuel, 2014.

[3] Premkumar S. NOX Reduction in Diesel Engine Using Electronically Controlled Selective Catalytic Reduction[J]. Middle-East Journal of Scientific Research, 2014, 20(11): 1365-1369.

[4] JothiThirumal B, Gunasekaran E J, Saravanan C G. Performance and Emission Analysis of Bio Diesel Fuelled Engine with Selective Catalyst Reduction (SCR)[J]. International Journal of Engineering and Technology (IJET)-Volume, 2013, 3.

[5] Valencia M, López E, Andrade S, et al. Proof of concept of the SCR of NOx in a real diesel engine exhaust using commercial diesel fuel and a full size Pt/beta zeolite/honeycomb monolith[J]. Catalysis Communications, 2014, 46: 86-89.

[6] Solaimuthu C, Chitra S, Rajasekaran P, et al. NOx Reduction of Diesel Engine with Madhuca Indica biodiesel using Selective Catalytic Reduction (SCR) in different flow rates[J]. International Organization of Scientific Research, 10 (5), 2014: 28-34.

[7] Rauch D, Albrecht G, Kubinski D, et al. A microwave-based method to monitor the ammonia loading of a vanadia-based SCR catalyst[J]. Applied Catalysis B: Environmental, 2014.

[8] Qiu T, Li X, Liang H, et al. A method for estimating the temperature downstream of the SCR (selective catalytic reduction) catalyst in diesel engines[J]. Energy, 2014, 68: 311-317. 